\title{
Environmental stochasticity and intraspecific competition influence the population dynamics of Culex quinquefasciatus (Diptera: Culicidae)
}

William T. Koval and Gonzalo M. Vazquez-Prokopec ${ }^{*}$

\begin{abstract}
Background: Members of the Culex pipiens complex (CX. pipiens quinquefasciatus in Southern USA) play a critical role in the spillover of urban arboviruses such as West Nile virus or St. Louis encephalitis virus. Field studies have shown strong correlation between the periodicity of rainfall events and larval proliferation. However, mechanistic determinants driving this relationship are poorly understood. We hypothesize that rainfall events decrease strain from intraspecific competition through the associated reduction of immature density and the introduction of detritus.

Results: To address our hypothesis, we used laboratory competition experiments to inform a deterministic matrix projection model consisting of an age-structured larval matrix coupled with a stage-structured adult mosquito matrix. Rain events were simulated in a competition-based metabolic age model and compared to a null model including environmental variability. Variable rain delays in two-event simulations showed optimal proliferation occurring with rain delays between 16 and 21 days when including density-dependent effects.

Conclusions: These results are comparable to the pattern observed in natural populations, indicating that $C X$. quinquefasciatus proliferation rates can be modeled mechanistically as a density-dependent system. The empirical understanding of density-dependence as it relates to environmental stochasticity provides a theoretical platform for the study of larval dynamics and the impact of larval control in this medically relevant disease vector.
\end{abstract}

Keywords: Density dependence, Population modeling, Culex quinquefasciatus, Vector management

\section{Background}

In the USA, members of the Culex pipiens complex (predominantly $C x$. pipiens and Cx. quinquefasciatus) have been identified as the principal vectors of flaviviruses such as West Nile virus (WNv) and St. Louis encephalitis virus (SLEv) [1-3]. Culex quinquefasciatus is considered the principal human WNv spillover vector in southern USA due to its high abundance, competence, and infection rates [1,3-7]. Although $C x$. quinquefasciatus populations have been the target of intense vector control, particularly once symptomatic human WNv cases are detected, realized treatment efficacy remains difficult to demonstrate [8-10]. In addition to application cost, vector

\footnotetext{
* Correspondence: gmvazqu@emory.edu

Department of Environmental Sciences, Emory University, Atlanta, GA 30322, USA
}

(c) The Author(s). 2018 Open Access This article is distributed under the terms of the Creative Commons Attribution 4.0 International License (http://creativecommons.org/licenses/by/4.0/), which permits unrestricted use, distribution, and reproduction in any medium, provided you give appropriate credit to the original author(s) and the source, provide a link to the Creative Commons license, and indicate if changes were made. The Creative Commons Public Domain Dedication waiver (http://creativecommons.org/publicdomain/zero/1.0/) applies to the data made available in this article, unless otherwise stated.

management in the Cx. quinquefasciatus system is limited by immature larval habitat characteristics $[9,11-13]$, fine scale heterogeneity in virus transmission $[7,14]$, and high levels of uncertainty in the prediction of disease outbreaks.

Culex quinquefasciatus requires a higher quality and variety of dissolved organics for survivorship to adulthood than do other mosquito species [15-18]. As $C x$. quinquefasciatus oviposit egg raft masses of approximately 200 coeval individuals [19], selection of high nutrient environments is a key factor for successful larval mosquito development [17, 20, 21]. Culex spp. mosquitoes are commonly found in high numbers in artificial containers, unattended pools, retention ponds, storm drains, catch basins, sewage systems and pit latrines [12, 13, 22-28]. The high nutrient loading of such habitats limit predator survival and 
release $C x$. quinquefasciatus from interspecific competition, leading to high larval densities that can become potentially vulnerable to intraspecific competition.

Culicine individuals subjected to higher larval densities exhibit delayed adult emergence, decreased fecundity, poor and uneven growth, and overall lower survivorship $[12,22,29-32]$. It is assumed that $C x$. quinquefasciatus mass accumulation follows other insect models in that consumption rates rise with biomass while efficiency of mass conversion decreases due to higher metabolic rates $[33,34]$. From this general relationship, it can be predicted that overall nutrient consumption of immature $C x$. quinquefasciatus depends upon the population age structure and that, in order to maintain the commonly observed high densities of larval habitats, nutrient loading must be substantial and frequent.

Rainfall events provide water and nutrient resources to larval habitats, particularly urban catch basins, leading to immediate and delayed effects on larval mosquito proliferation [35]. Despite the flushing of culicine eggs and pupae from flooded habitats [36], larval proliferation within habitats has been shown to increase on average four days after a rain event [12, 37-39]. Adult proliferation has also been demonstrated to be time-lag associated with rainfall events. In Chicago, IL, approximately two weeks are required for oviposition and hatching to establish adult emergence peaks and an optimal periodicity of three weeks between rainfall events has been shown to increase the magnitude of these peaks [37, 38]. Despite empirical knowledge that rainfall events impact $C x$. quinquefasciatus proliferation, the biological mechanisms driving this relationship are poorly understood and rarely considered within mathematical models [35, 37-40].

In this study, we linked larval competition experiments with mathematical models to understand the mechanistic basis of the association between rainfall and $C x$. quinquefasciatus population dynamics. Our research hypothesis is that $C x$. quinquefasciatus intraspecific larval competition is the driving mechanism of demographic responses, both immediate and latent, to rainfall regimes. To address this hypothesis, we first experimentally quantified the contribution of nutrient loading and population density to the larval dynamics of $C x$. quinquefasciatus. Experimental data then informed a deterministic mathematical model exploring the interactive effects of rainfall, nutrient loading, and density-dependence on $C x$. quinquefasciatus population size.

\section{Methods}

\section{Life table parameter estimation}

Field measurements and controlled experiments allowed quantification of natural fecundity and the influence of nutrient availability on immature life history traits, respectively. Fecundity was estimated by collecting naturally occurring eggs from Baker Woods (an urban forest patch located in Emory University, Atlanta, GA [17]) following the methods described by Chaves et al. [23]. Briefly, oviposition traps were left overnight and culicine egg raft masses were collected the following morning. A total of 40 coeval egg rafts were used for fecundity and fertility estimation. The number of eggs per raft was counted using a stereomicroscope (Leica IC80, Leica Microsystems, Wetzlar, Germany). After counting, rafts were placed individually inside a polystyrene vial with water to allow for larval hatching inside an insect growth chamber (6025-1, CARON Products, Marietta, OH, USA) set at $20{ }^{\circ} \mathrm{C}$ and $80 \%$ relative humidity, RH. Fertility was calculated for each egg raft by dividing the total larvae hatched by the total number of eggs. Four larvae from each raft were kept until fourth-instar to later identify egg rafts to species [41].

The effect of nutrient availability on immature life history traits (survivorship, time to stage change and consumption rate) was measured by subjecting $C x$. quinquefasciatus larval cohorts to a four-level nutrient gradient (Table 1). Nutrient levels were informed by a pilot study that found no density-dependent effects within the high nutrient treatment and significant (>95\%) mortality within the low nutrient treatment.

This design was replicated five times over the four treatments. Twenty mosquito breeding chambers (1425DG, Bioquip, Rancho Dominguez, CA, USA) were filled with $400 \mathrm{ml}$ of untreated water from Peavine Creek (an unpolluted stream running close to Emory Campus). A stock nutrient solution was created from $300 \mathrm{mg}$ of baker's yeast (B2C, LeSaffre, Marcq-en-Baroeul, France) and $300 \mathrm{mg}$ fish food (971,168, Carolina Biological Suuply Co, Whitsett, NC, USA) dissolved in $0.9 \mathrm{~L}$ of creek water (1.5 mg nutrients $/ \mathrm{ml}$ ) and diluted to match nutrient treatment levels at consistent volume (Table 1).

Forty first-instar larvae, collected from four different egg rafts (10 larvae per raft), were placed in each breeding chamber approximately $24 \mathrm{~h}$ after hatching. Breeding chambers were stored inside the insect growth chamber $\left(20{ }^{\circ} \mathrm{C}, 80 \% \mathrm{RH}\right)$ and mosquito development was monitored daily. Development was measured by counting and removing shed IV instar molt casings (time to pupation) and pupal molt casings (time to emergence). Daily

Table 1 Nutrient concentration levels used for all experiments estimating life-table parameters

\begin{tabular}{llll}
\hline Treatment ID & $\begin{array}{l}\text { Starting nutrient } \\
\text { concentration }\end{array}$ & $\begin{array}{l}\text { Starting nutrient } \\
\text { availability }\end{array}$ & $\begin{array}{l}\text { Stock added } \\
\text { daily }\end{array}$ \\
\hline High & $0.3 \mathrm{mg} / \mathrm{ml}$ & $120 \mathrm{mg}$ & $9 \mathrm{mg}$ \\
Mid-High & $0.15 \mathrm{mg} / \mathrm{ml}$ & $60 \mathrm{mg}$ & $4.5 \mathrm{mg}$ \\
Mid-Low & $0.075 \mathrm{mg} / \mathrm{ml}$ & $30 \mathrm{mg}$ & $2.25 \mathrm{mg}$ \\
Low & $0.0375 \mathrm{mg} / \mathrm{ml}$ & $15 \mathrm{mg}$ & $1.125 \mathrm{mg}$ \\
\hline
\end{tabular}


mortality was calculated for each breeding chamber by subtracting the number of fourth-instar molt casings and number of live larvae from the number of live larvae on the previous day. Monitoring ended once all adults emerged.

\section{Statistical analyses of experimental data}

We used Gaussian Generalized Linear Models (GLMs) to predict survivorship over time across the density gradient. We did not account for random effects due to high synchrony of development and mortality across replicates within each treatment. Developmental synchrony also demonstrated that the assumption of independent rightcensorship within Kaplan-Meier plots was invalid [42]. All other life history traits of immature individuals (pupation rate, aggregate survivorship, fecundity) were reported by calculating their mean and variance. Pupation rate and overall survivorship from larvae to pupae and pupae to adult were compared with analysis of variance (ANOVA). Where significant effects occurred, comparisons were made and alpha levels were adjusted using Tukey Honestly Significant Difference (HSD) tests.

\section{Mathematical models}

Two models linking larval development and environmental conditions were parameterized using values from our experiments and published literature. Model $\mathrm{N}^{*}$ was a stage-based matrix projection following the work of Lefkovitch et al. [43], and was developed with the objective of providing a null model responsive to extrinsic environmental factors but ignorant of the intrinsic biological factors of Cx. quinquefasciatus (Fig. 1). Female fecundity and fertility values were based on our field observations of egg rafts. We used average time to pupation and adult emergence across experimental treatments as estimates of daily stage change rates in the matrix. Life expectancy in adults was set to 22 days with a gonotrophic cycle of 7 days $[19,44]$.

Model $\mathrm{N}^{*}$ predictions were contrasted with an alternative model designed to assess the competition hypothesis of the study. This alternative matrix model (Model A*) relied on density-dependent larval interactions determined by the equation:

$$
\mathrm{S}_{\mathrm{j} . \mathrm{t}}=\omega_{\mathrm{t}} / \Omega_{\mathrm{j}}
$$

where the survivorship (S) of cohort $j$ at time $t$ is equal to the nutrients $(\omega)$ available at time $t$ divided by a coefficient of competition $(\Omega)$ upon cohort j.

In a coeval population, $\Omega$ is directly proportional to the number of immature individuals within the environment. Eq. 1 provided the framework to translate GLM coefficients of larval mortality $(\mu)$ into consumption rate functions for

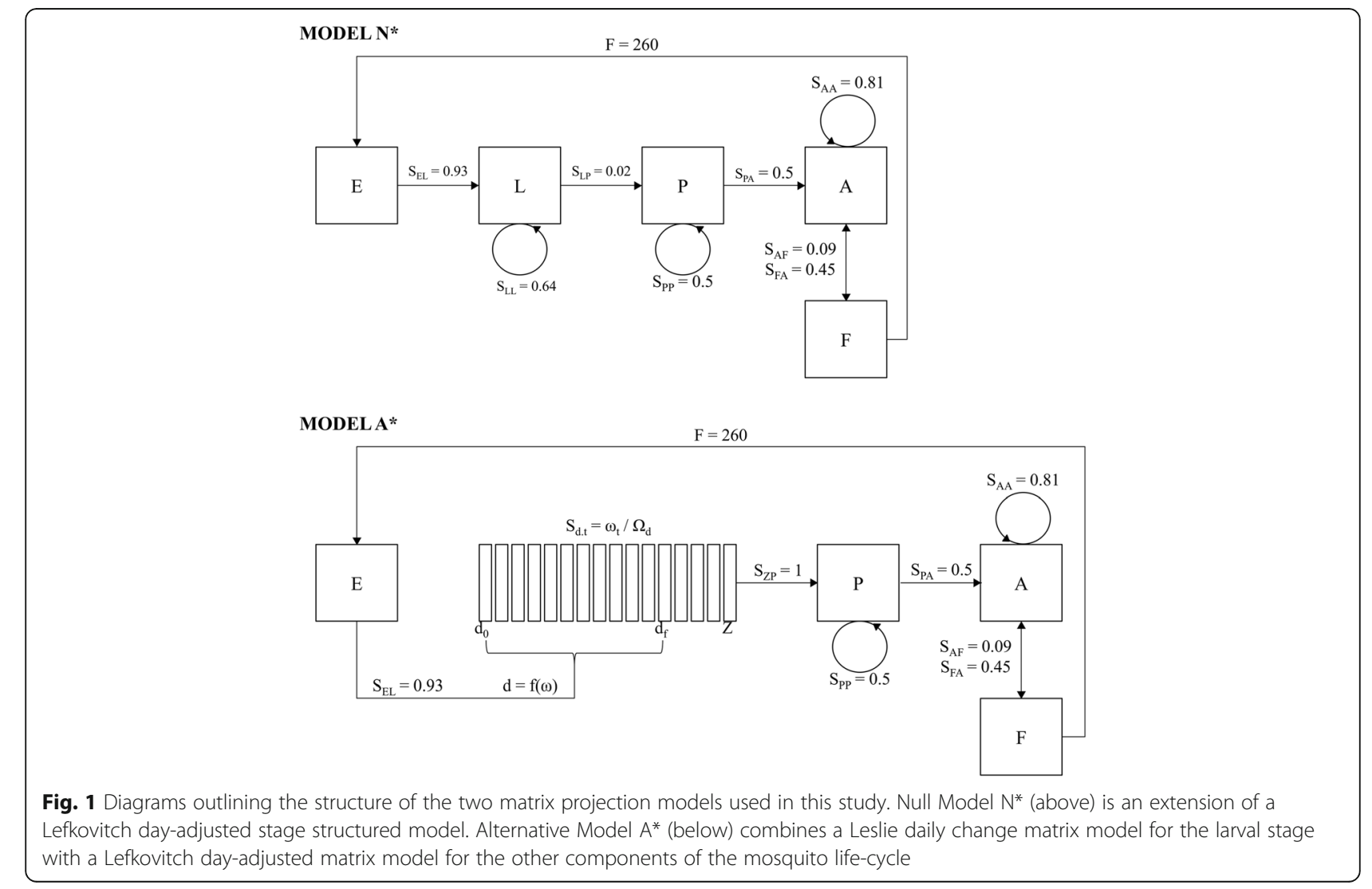


Model $\mathrm{A}^{*}$ by estimating larval survivorship over time within resource treatment group $\omega\left(S_{\omega}(\mathrm{t}), \mathrm{Eq}\right.$. 2). We fitted mortality rate models rather than observed survivorship in order to eliminate the false inclusion of stage changes as density-dependent deaths.

$$
S_{\omega}(t)=\left(1-\operatorname{GLM}_{\mathrm{g}}\left(\mu_{\omega} \sim \mathrm{t}\right)\right) * 40
$$

The known value of $\omega$ informed the final consumption rate function over time, which was assumed to be exponential. The central assumption of this calculation is that density-dependent effects are occurring as a result of zero time-lag absolute resource exploitation. Individuals consume their mass-dependent daily nutrient requirement and, if this requirement cannot be met for all individuals, mortality will occur at the daily timescale to fit $\mu$ to $\omega$. This allows for calculation of the consumption rate function $C_{\omega}(t)$ for a given treatment, as follows:

$$
\mathrm{C}_{\omega}(\mathrm{t})=\omega(\mathrm{t}) / S_{\omega}(\mathrm{t})
$$

In a mixed age population, consumption rates vary along the predicted curve $\mathrm{C} \omega(\mathrm{t})$ from metabolic age 1 through Z, after which larvae pupate. Within Model A*, we expanded the larval stage of Model $\mathrm{N}^{*}$ into daily metabolic ages $\left(\mathrm{d}_{1}-\mathrm{z}\right)$ that are defined by consumption instead of explicit chronological age. The low nutrient treatment consumption function $\mathrm{C}_{0.375}(\mathrm{t})$ defined the consumption rates for each metabolic age. The y-intercepts of consumption functions from the other three nutrient treatments were used to determine the relationship between nutrient availability and nutrient exploitation upon hatching, producing variable metabolic ages of first-instar larvae. The maximum metabolic age $\left(\mathrm{d}_{\mathrm{f}}\right)$ of first-instar larvae upon hatching was set to be the age at which $\mathrm{C}_{0.375}\left(\mathrm{~d}_{\mathrm{f}}\right)$ was equal to the intercept $\mathrm{C}_{3}(0)$. The final larval metabolic age, $\mathrm{Z}=38$ days, was determined by time to pupation from $\mathrm{d}_{\mathrm{f}}=33$ days.

Within the larval sub-matrix of Model A*, daily survivorship values for each metabolic age cohort were calculated as a function of resources available. In the simulated environment, the coefficient of competition, $\Omega$, is calculated by the summed competitive effects of all cohorts ( 1 through $\mathrm{Z}$ ) on cohort $\mathrm{j}$ in the equation:

$$
\Omega_{j}=\sum_{1 \rightarrow Z}^{i} C_{i} N_{i} / C_{j}
$$

where the consumption rate $(\mathrm{C})$ is treated as a proportional competitive effect, allowing the competition coefficient to represent the number of cohort-equivalent individuals competing with cohort $j$. This mathematical consideration favors larger cohorts by reducing the relative competitive effect exerted upon them by smaller cohorts, as is the case in natural systems [30]. Metabolic age $\mathrm{Z}$ permits larvae to pupate and enter the Lefkovitch matrix stages of the model that maintained structure from Model $\mathrm{N}^{*}$ (e.g., adults, pupae, eggs). We termed Model $A^{*}$ a focal stage matrix, structured as explicit metabolic ages nested within daily-adjusted stage change probabilities. The projection cycles of Models $\mathrm{A}^{*}$ and $\mathrm{N}^{*}$ are shown in Fig. 1. A description of all metrics and their values can be found in Table 2. Models were constructed, projected, and analyzed using $\mathrm{R}$ statistical software [45].

\section{Model assumptions and initial conditions}

Ecologically, Model A* assumes an absolute exploitative competition response within the larval population. This means that each day, larvae will consume the amount of nutrients designated by their metabolic age that are available to them. If this immediate need cannot be met, the model then assumes that larval mortality operates on a zero time-lag response if nutrients are exhausted from the environment. Biologically, Model A* assumes a low efficiency of resource processing and mass accumulation, particularly in low nutrient environments, as seen in our analysis of in-lab observations. Low efficiency is compounded by the assumption that larvae do not eat the processed waste of other larvae and do not consume the bodies of larvae which have died as a consequence of density-dependence, upregulating the rate at which nutrients leave the simulated environment. In reference to adult populations, both models remove males through

\begin{tabular}{|c|c|}
\hline Parameter & Description \\
\hline $\mathrm{N}_{\mathrm{t}}$ & Population at time $t$ \\
\hline$\omega(\mathrm{t})$ & $\begin{array}{l}\text { Resources available over time within an experimental } \\
\text { treatment }\end{array}$ \\
\hline$\omega_{t}$ & Resources available within an environment at time t \\
\hline $\mathrm{C}_{\omega}(\mathrm{t})$ & $\begin{array}{l}\text { Experimentally determined consumption rate function for } \\
\text { resource treatment group } \omega\end{array}$ \\
\hline$C_{j}$ & Consumption rate that determines metabolic age of cohort $j$ \\
\hline$\Omega_{\mathrm{j}}$ & $\begin{array}{l}\text { Coefficient of competition showing exploitative effects of all } \\
\text { cohorts present in an environment on cohort j }\end{array}$ \\
\hline d & $\begin{array}{l}\text { The metabolic cohort that first-instar larvae join upon } \\
\text { hatching }\end{array}$ \\
\hline$d_{f}$ & $\begin{array}{l}\text { The highest metabolic cohort that newly hatched larvae } \\
\text { can join }\end{array}$ \\
\hline Z & $\begin{array}{l}\text { The final metabolic age cohort in the model with the } \\
\text { largest consumption rate }\end{array}$ \\
\hline$\mu_{\omega}(t)$ & Mortality curve of a given resource treatment group $\omega$ \\
\hline $\mathrm{S}_{\omega}(\mathrm{t})$ & Survivorship over time within resource treatment group $\omega$ \\
\hline$S_{j . t}$ & The survivorship of cohort $\mathrm{j}$ at time $\mathrm{t}$ \\
\hline $\mathrm{F}$ & Fecundity of gravid females \\
\hline E & Rain event day \\
\hline
\end{tabular}
the adult sub-matrix, discounting the mating process by

Table 2 List of parameters and functions used in the models 
assuming random mixing. Model $\mathrm{A}^{*}$ requires both males and females in the larval stage due to their equal contribution to competition effects.

At the simulated system scale, the model assumes consistent temporal distribution of detritus, causing rain events, even those close together in time, to load the same amount of detritus into larval habitats. For simplicity and model tractability, we generated models simulating population dynamics on a single habitat type with constant size and water-holding capability. Our modeled habitats are equivalent to roadside catch basins, as they have been well characterized in their Culex spp. larval dynamics and response to rainfall [39], are known to maintain high abundance of $C x$. quinquefasciatus [37, 46], are widely distributed in urban areas of the USA, and are the most commonly targeted structure in urban larval control campaigns $[9,11,47,48]$. The model also assumes that the effects of evaporation within the system are negligible, and that oviposition site selection of $C x$. quinquefasciatus females is strictly adherent to catch basin habitats [23, 24].

After determining the matrix values of Models $\mathrm{N}^{*}$ and $\mathrm{A}^{*}$, we simulated the projection cycles of each model with two rain events of equal size in an environment of 52 simulated catch basins that held a normal distribution with a mean $225 \pm 11$ g of detritus. Four kilograms of detritus were introduced to each simulated catch basin for a total of $208 \mathrm{~kg}$ introduced into the system. We used this value for an assumed $10 \mathrm{~m}^{2}$ drainage area per catch basin and consistent average of $400 \mathrm{~g}$ detritus/ $\mathrm{m}^{2}$. The decay rate was set to $0.1 \%$ of matter being converted into directly consumable resources for larvae each day through bacterial decomposition [49]. The catch basin count is approximately the size of past study sites in the Atlanta area [7]. Rainfall size was assumed to be consistent for all simulations to maintain realism of simulated flushing and nutrient delivery by water collected over the large drainage area of these basins.

Simulations of single rain event systems with 200 adults were observed for timing to first peak of adults and equilibrium age distribution. In double-event simulations, an initial population distribution of 363 eggs, 592 larvae, 20 pupae and 23 adults per catch basin was selected for model runs based on typical adult resting behavior of $C x$. quinquefasciatus individuals observed in the field (Vazquez-Prokopec et al., unpublished) and the equilibrium stage distribution from Model $N^{*}$. In both models, rain events flushed eggs and pupae from the population with no time delay. We assumed two independent scenarios of the impact of rainfall on immature stages where (i) all eggs and pupae were flushed from the system or (ii) $50 \%$ of eggs and pupae were flushed. Larvae remained in the system following previous work performed on flush evasion behavior of culicine larvae [36].
Proliferation rates of Models $\mathrm{N}^{*}$ and $\mathrm{A}^{*}$ were quantified by mean number of adults produced per catch basin after 75 days. Paired events $\mathrm{E}_{1}=2$ and $\mathrm{E}_{2}=2+\mathrm{t}$ were delayed on a lag ranging from $t=1$ to $t=35$. The mean proliferation of adults was determined for each lag and each subset of lags by week. Means were taken as a fraction of productivity from single rain event simulations $\mathrm{E}=2$. A 75 day monitoring period was selected in order to capture the first peak and decline of adult proliferation seen within the Model A* single-event simulation.

Finally, we measured sensitivity of Models $\mathrm{N}^{*}$ and $\mathrm{A}^{*}$ to the reduction of larvae or adults, the two targets of vector control. The same 52 catch basin system used to determine relative productivity in response to rain event delays was simulated with $E_{1}=2$ and $E_{2}$ ranging from 18 to 21 . Both models included two scenarios simulating a reduction of 50 or $75 \%$ of the initial population of larvae or adults. Sensitivity was calculated by dividing the total number of adult mosquitoes that emerged in scenarios simulating a reduction in vector abundance by the total number of mosquitoes in scenarios in which vector abundance was not modified. In these sensitivity analyses, we assumed 100\% flushing of eggs and pupae from the simulated environment based on literature, our results, and observations from the field [13, 36].

\section{Results}

\section{Life table parameter estimation}

Culex quinquefasciatus fecundity was, on average $( \pm 95 \%$ CI), $258 \pm 23.0$ eggs. Hatch rate was, on average, $91.0 \pm$ $6.5 \%$ and highly synchronized, occurring $2.16 \pm 0.13$ days after oviposition. When applied to Models $\mathrm{N}^{*}$ and $\mathrm{A}^{*}$, we assumed hatch rate to be 2 days for simplicity of calculation. Life history trait parameters (survivorship, rate of stage change) of larval competition experiments are listed in Table 3. Pupal survivorship to adulthood was consistent across treatments, ranging from 93.0 to $99.0 \%$ $\left(F_{(3,527)}=0.5 ; P=0.73\right)$. Survivorship from the larval stage to pupation decreased along the nutrient gradient from $99 \pm 1.0 \%$ in the highest nutrient environment to $23.5 \pm$ $11.6 \%$ in the low nutrient treatment (Table 3). Strength of competitive effects was inversely related to nutrient availability, with significantly decreased larval survivorship in the two lower nutrient treatments compared to the two higher nutrient treatments $\left(F_{(3,796)}=102.6 ; P<0.001\right)$. The difference between mean time to pupation and mean time to emergence for all individuals within the experiments was $2.8 \pm 0.4$ days and did not significantly differ.

GLM-predicted mortality curves for each nutrient treatment (Table 4) showed significant associations between time and larval death in the Low through Mid-High treatments (Fig. 2). GLMs were calculated as a linear relationship between cohort mortality and time: 
Table 3 Survivorship and stage change rates quantified from larval competition experiments

\begin{tabular}{lll}
\hline Nutrient treatment & $\begin{array}{l}\text { Survivorship } \\
(\text { mean } \pm 95 \% \mathrm{Cl})^{\mathrm{a}}\end{array}$ & $\begin{array}{l}\text { Stage change rate } \\
(\text { mean days } \pm 95 \% \mathrm{Cl})^{\mathrm{a}}\end{array}$ \\
\hline High ( $\left.\mathrm{t}_{0}=3 \mathrm{mg} / \mathrm{larva}\right)$ & & $12.2 \pm 3.43$ \\
Larval pupation & $99.0 \pm 1.0^{\mathrm{A}}$ & - \\
Pupal emergence & $98.5 \pm 1.0^{\mathrm{A}}$ & $15.2 \pm 3.3^{\mathrm{A}}$ \\
Total emergence & $97.5 \pm 1.6$ & $15.4 \pm 7.3$ \\
Mid-High ( $\mathrm{t}_{0}=1.5 \mathrm{mg} /$ larva) & - \\
Larval pupation & $94.5 \pm 3.9^{\mathrm{A}}$ & $18.42 \pm 7.4^{\mathrm{AB}}$ \\
Pupal emergence & $94.5 \pm 2.0^{\mathrm{A}}$ & \\
Total emergence & $95.0 \pm 4.3$ & $23.8 \pm 13.2$ \\
Mid-Low (t $\mathrm{t}_{0}=0.75 \mathrm{mg} /$ larva) & - \\
Larval pupation & $48.5 \pm 7.1^{\mathrm{B}}$ & $26.6 \pm 12.6^{\mathrm{BC}}$ \\
Pupal emergence & $99.0 \pm 1.0^{\mathrm{A}}$ & \\
Total emergence & $51.5 \pm 7.4$ & $31.7 \pm 14.0$ \\
Low (to $\mathrm{t}_{0}=0.375 \mathrm{mg} /$ larva) & \\
Larval pupation & $23.5 \pm 11.6^{\mathrm{C}}$ & - \\
Pupal emergence & $93.0 \pm 5.0^{\mathrm{A}}$ & $33.9 \pm 12.3^{\mathrm{C}}$ \\
Total emergence & $24.0 \pm 5.7$ &
\end{tabular}

atetter groups A-C denote significant differences between experimental treatments by HSD $a<0.05$

$$
\mu_{\omega}(t)=\mathrm{N} * t+\text { intercept }
$$

The steepest GLM slope occurred within the low nutrient treatment, as assumed by the survivorship data in Table 3, which was predicted to lose an average of $4.1 \pm 0.15 \%$ of larvae each day in the period that the treatment experienced density dependent effects (days 3-23) (Table 4, Fig. 2).

The basal consumption rate of first-instar larvae upon hatching (i.e. the intercept of the consumption function) increased with starting per capita nutrients from $\mathrm{C}_{0.375}(0)=0.31 \mathrm{mg}$ to $\mathrm{C}_{1.5}(0)=1.51 \mathrm{mg}$ of daily consumption per first-instar larva. When the per capita consumption rate functions were summed over the duration of the experimental trial (Fig. 3), pupation was associated with a consistent predicted lifetime cumulative consumption of $32.8 \pm 11.6 \mathrm{mg}$ per larva.

\section{Model application}

In Model $\mathrm{N}^{*}$, single rain events at the start of new simulated seasons with initial populations of 200 adults approached equilibrium relative distributions of 0.36 eggs, 0.59 larvae, 0.02 pupae and 0.02 adults. Upon adding intrinsic competition through Model $\mathrm{A}^{*}$, total productivity approached a parabolic shape consistent with our observed data and growth trends in urban environments (Fig. 4) [33, 34]. After resources diminished through direct decomposition and consumption by larvae, peaks of adult proliferation continued to occur with dampened larval oscillations.

The equilibrium distribution of Model $\mathrm{N}^{*}$ was used to define initial populations of double-event simulations for both Model $\mathrm{N}^{*}$ and $\mathrm{A}^{*}$. Total productivity estimated by Model $\mathrm{N}^{*}$ in double-event simulations increased exponentially towards baseline proliferation of single-event simulations only after rainfall periodicity was greater than 40 days. Variable impact of rainfall on flushing of immatures (50 or $100 \%$ mortality in eggs and pupae) produced the same qualitative trend (Fig. 5). The intensity of suppressed proliferation due to a second rainfall event was proportional to the fraction of immatures flushed out of the system. In Model $\mathrm{A}^{*}, 3$ week spacing between rain events led to consistent high proliferation distributions with $1.52 \pm 0.06$ increases in productivity from a second rain event (Fig. 5). When only 50\% of eggs and pupae were flushed from the system, peaks in proliferation shifted to favor smaller rain delays, between 2 to 3 weeks, but were qualitatively consistent with $100 \%$ flushing scenarios. The percent change in proliferation was also quantitatively consistent, showing $1.49 \pm 0.04$ fold increases in productivity. Though both scenarios reflect the natural response of $C x$. quinquefasciatus populations to rainfall periodicity, $100 \%$ flushing of eggs and pupae more closely resembles the timing of proliferation blooms observed in the field.

Sensitivity of Model $\mathrm{N}^{*}$ and $\mathrm{A}^{*}$ to reductions in either initial larval or adult populations showed that both were more sensitive to adult perturbation (Fig. 6). Adult reduction by $75 \%$ of the initial population yielded $69.1 \%$ reduction and halted productivity in Model $\mathrm{N}^{*}$ and $\mathrm{A}^{*}$, respectively. However, larval reduction by $75 \%$ only reduced proliferation by $30.9 \%\left(\mathrm{~N}^{*}\right)$ and $14.9 \pm 3.2 \%\left(\mathrm{~A}^{*}\right)$ of final productivity.

\section{Discussion}

By linking field observations, experiments, and mathematical models, we provide evidence of the strong influence

Table 4 Generalized Linear Models fitted to mortality data curves in low nutrient environments

\begin{tabular}{llll}
\hline Nutrient treatment & Slope \pm SE & Intercept \pm SE & Experimental day range \\
\hline High $\left(\mathrm{t}_{0}=3.0 \mathrm{mg} / \mathrm{larva}\right)$ & na & $0.2 \pm 0.32$ & na \\
Mid-High $\left(\mathrm{t}_{0}=1.50 \mathrm{mg} / \mathrm{larva}\right)$ & $0.3 \pm 0.06^{*}$ & $-0.2 \pm 0.75$ & $0-20$ \\
Mid-Low $\left(\mathrm{t}_{0}=0.750 \mathrm{mg} / \mathrm{larva}\right)$ & $2.3 \pm 0.09^{*}$ & $-12.7 \pm 1.61^{*}$ & $7-27$ \\
Low $\left(\mathrm{t}_{0}=0.375 \mathrm{mg} / \mathrm{larva}\right)$ & $4.1 \pm 0.15^{*}$ & $-16.6 \pm 2.12^{*}$ & $3-23$ \\
\hline
\end{tabular}

* $P<0.001$ by Gaussian GLM

Abbreviations: na, not applicable; SE, standard error 


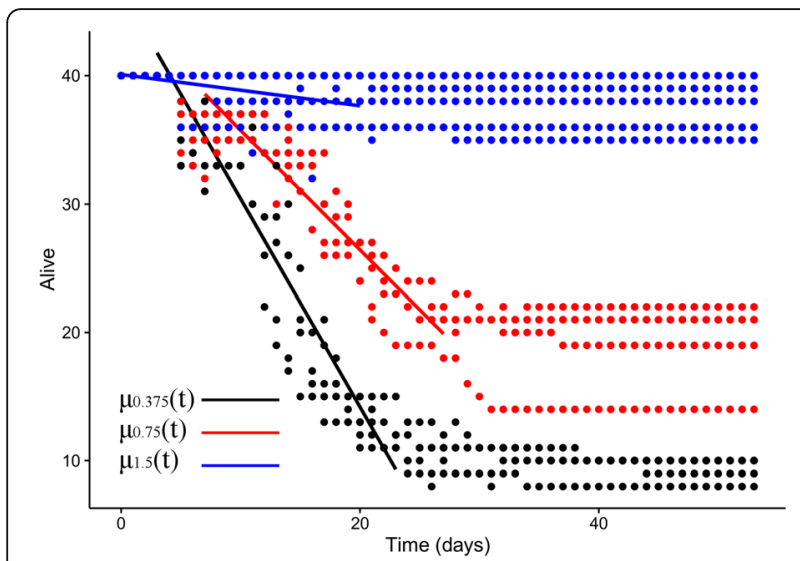

Fig. 2 Survivorship data (points) quantified from larval competition experiments performed used to predict mortality rates (through Generalized Linear Model lines) over the period in which densitydependent effects operated. Nutrient treatments are represented by color, excluding the highest nutrient treatment in which no density dependent effects were observed

that environmental stochasticity and intraspecific competition have in $C x$. quinquefasciatus populations. Rain events are a bottom-up force influencing nutrient loading and per-capita larval consumption rates. Additionally, intraspecific competition in the larval stage stabilizes population size through differential larval mortality. Together, both forces influence rates of adult productivity and explain boom-boost dynamics in $C x$. quinquefasciatus abundance occurring after a rain event. Our study also introduces a novel deterministic population matrix model that more adequately tracks metabolic age and per-capita consumption rates, leading to more realistic $C x$. quinquefasciatus population dynamics.

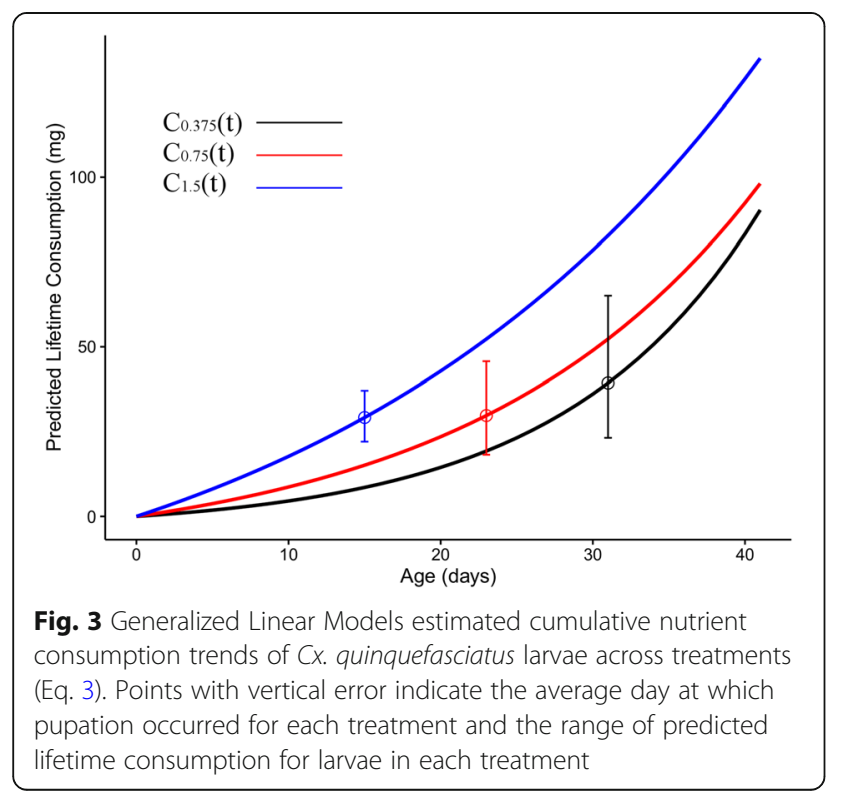

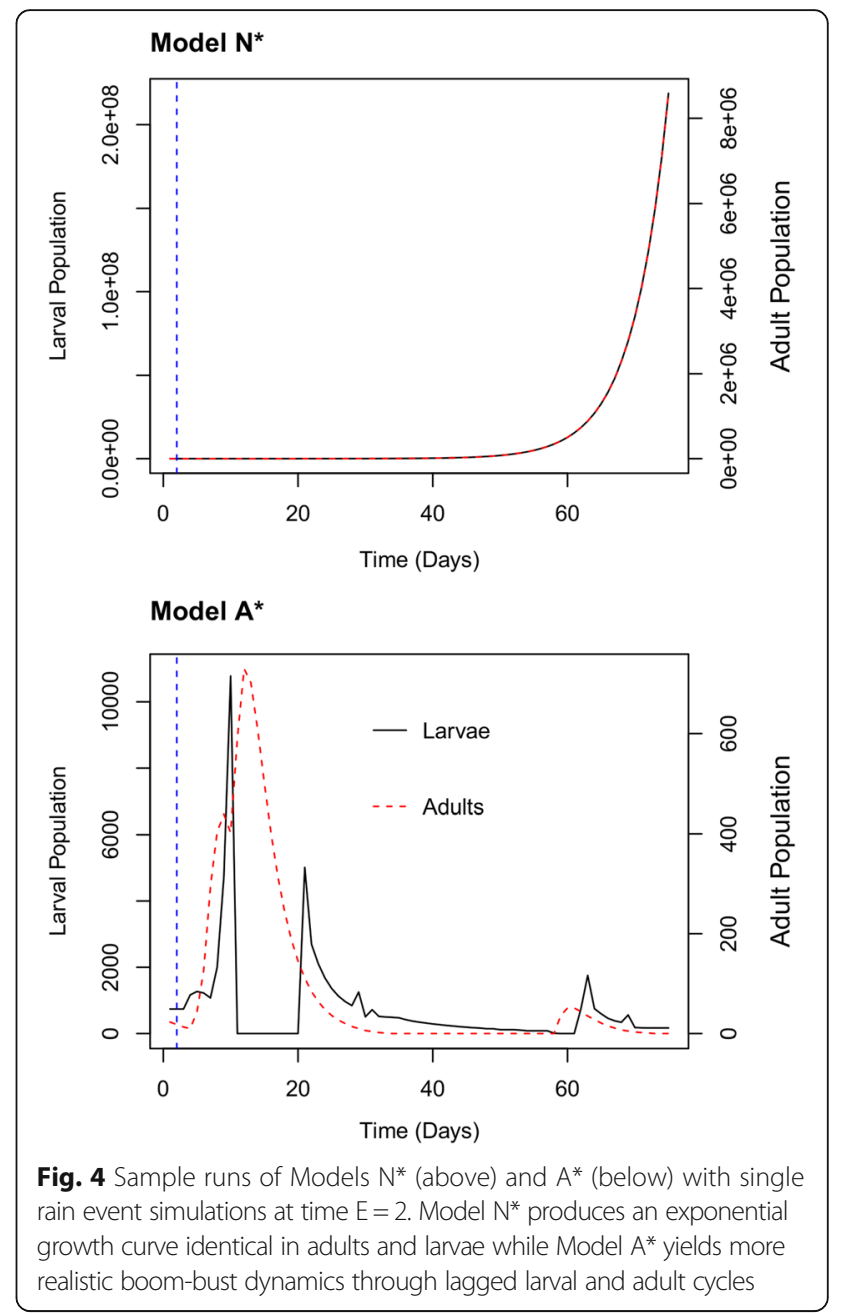

Biologically, our empirical calculations of nutrient acquisition and larval competition in Cx. quinquefasciatus are in agreement with previous studies $[15,18,23,29,50]$. Survivorship to pupation varied across treatments, with estimates of lifetime resource acquisition remaining consistent in low nutrient environments while time to pupation increased by a factor of three (Table 3). Nutrient loss due to metabolism in a prolonged larval stage would lead to reduced vector body size and ultimately reduced fecundity upon emergence [19]. Thus, we propose that a multiplicative effect of decreased survivorship and decreased fecundity in low nutrient environments have the potential to limit population growth in $C x$. quinquefasciatus. When incorporated into our mathematical model, such interactive effects were key in explaining simulated boom and bust dynamics and the observed population response of $C x$. quinquefasciatus to rain events.

During the stable population period of single-event simulations (i.e. after the initial larval bloom), per capita survival to pupation was higher than in the volatile, exponential growth period of colonization, suggesting 

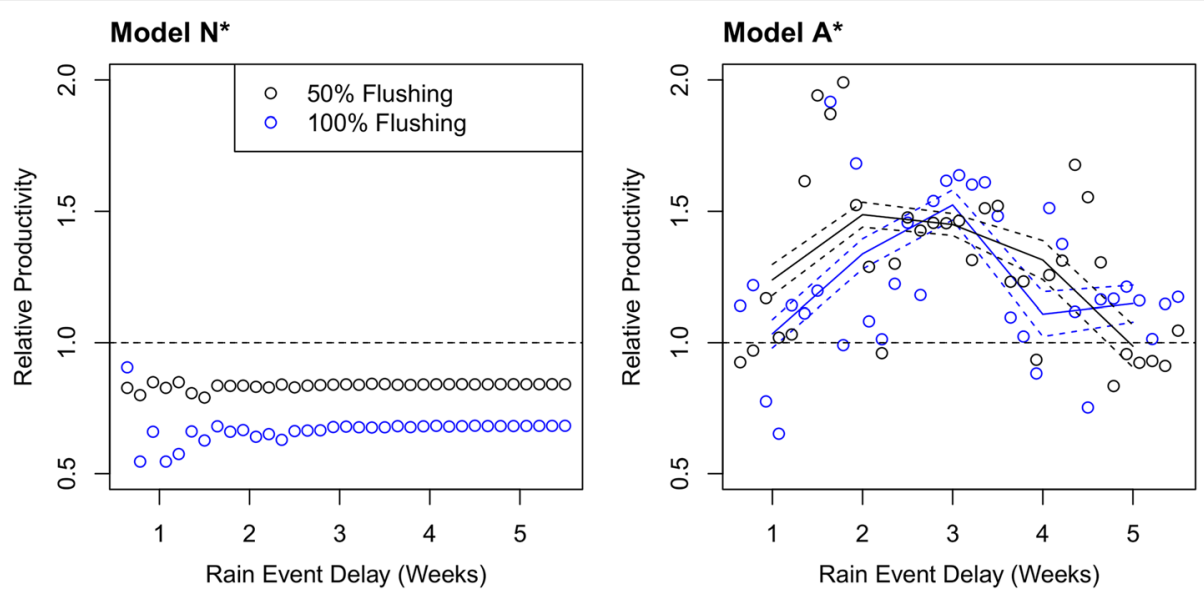

Fig. 5 Adult productivity predicted by Model $N^{*}$ (left) and Model $A^{*}$ (right) across a gradient of rainfall periodicity ( $x$-axis indicates the time gap in between two rain events). Relative productivity is a comparison between double-event simulations and a single-event simulation on the same first day $(E=2)$. Points show mean population response across 52 simulated catch basins

increased survivorship and metabolic efficiency at lower abundance or at high nutrient levels. Knowledge of population age distribution within a system and how that system responds to nutrient loading is therefore critical to understanding population response to environmental disturbance regimes or larvicide application. Insecticide-based larvicides (e.g. those that directly lead to larval mortality, such as Bacillus thuringiensis, bti) that present low efficacy on larval mortality in a catch basin $[9,11,48]$ could be relieving the population from strong competitive pressure, leading to an initial reduction in productivity but a rapid bounce-back of populations after rain events flush or dilute chemicals in catch

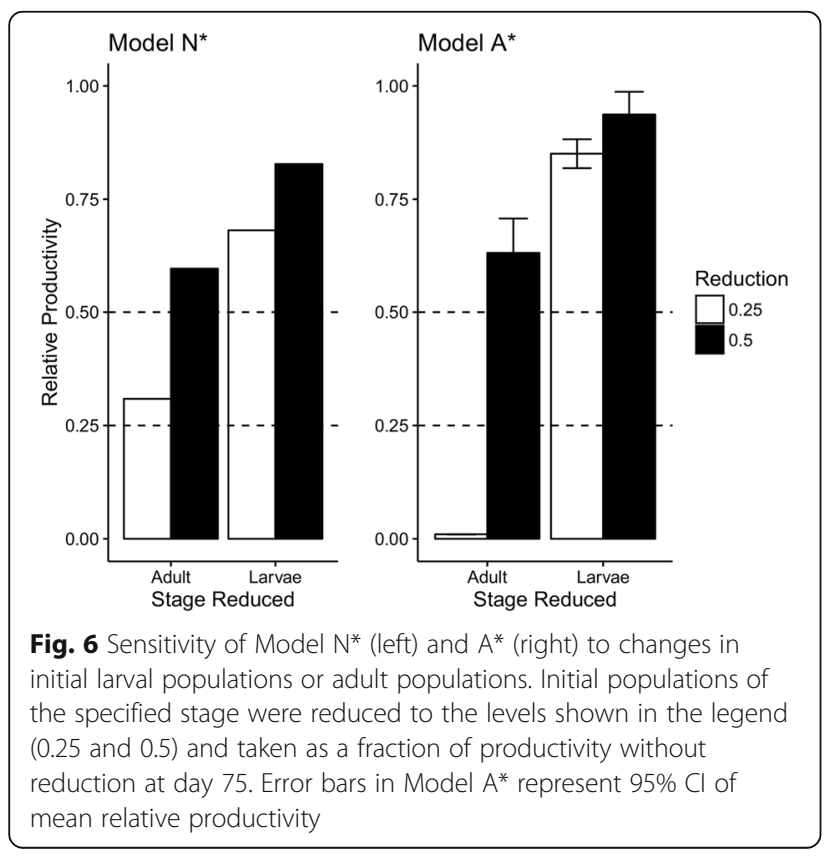

basins. Conversely, insect growth regulators (e.g. pyriproxyfen), which reduce adult emergence and not larval survival, would impact two components of larval dynamics: limiting adult emergence and maintaining high density-dependent mortality in the larval stage [51]. Such a relationship is supported through our investigation of Model $\mathrm{A}^{*}$ sensitivity to adult and larval perturbation. The interaction between competition release and insecticide regime efficacy, though little studied, can have high value in informing vector control strategies relying on larval control $[1,9,11,48,52]$.

Multiple vector control approaches are implemented to control WNv vectors in the USA $[8,9,11,48,53-58]$. While adulticiding is generally used in response to widespread human transmission or elevated mosquito infection rates, larviciding can be implemented both preventively and in combination with adulticiding. Larvicidal efficacy suffers from low residual power, leading to a need for frequent reapplication $[9,11,47]$. Our study suggests that formulations that do not alter population density but influence adult emergence will have a higher impact in culicines. Furthermore, designing novel molecule delivery modes that can endure rainfall flushing and rapidly dissolve in the water column will likely impact the population increase observed following rain events. Given the challenges that adulticiding approaches face in urban areas of the USA [54-56], effective vector control will depend on integrated management plans that utilize wellimplemented larviciding as an important tool for reducing vector abundance and preventing WNv spillover. Alternatively, devising approaches to modify roadside catch basin structures to make them mosquito-free, such as those described in Souza et al. [59], can be another approach to impact rapid $C x$. quinquefasciatus adult proliferation in urban areas. 
We acknowledge several limitations of our study. Although the inclusion of density-dependent mechanisms (Model $\mathrm{A}^{*}$ ) recreated patterns of environmental response described in the literature, we are aware of other potential factors that can influence such population behavior. In addition to the influence of detrital loading on larval populations, natural systems are sensitive to temperature effects and rainfall intensity. Unaccounted for in the simulated system, these parameters may influence the speed and response of populations to environmental stochasticity. Future work will aim to expand our modeling effort to include more realistic environmental drivers (temperature-driven development and consumption rates) as well as a tractable epidemiological link to our purely entomological models.

\section{Conclusions}

Driven by detrital loading through stochastic rain events, density-dependent interactions may be overlooked due to the high larval population levels found within $C x$. quinquefasciatus larval habitats. Our data and models demonstrate that such density-dependent effects can have dramatic population-level impacts, driving larval productivity and adult $C x$. quinquefasciatus population response to rain events. Our study therefore provides a theoretical platform for the study of immature populations and opens the door for more explicit explorations of the impact of larval and adult control in this medically relevant disease vector.

\section{Additional file}

Additional file 1: Annotated code performed in $\mathrm{R}$ and used to generate all models presented in this article. (R $30 \mathrm{~kb}$ )

\section{Abbreviations \\ ANOVA: Analysis of variance test; GLM: Generalized linear model; HSD: Tukey's honestly significant difference test; SE: Standard error; SLEv: Saint Louis encephalitis virus; WNv: West Nile virus}

\section{Acknowledgements}

The authors would like to thank Dr Michael Dunbar and Joseph McMillan for helpful comments and input on the design and analysis of experimental data.

\section{Funding}

This research was funded through the Lester Grant of the Environmental Sciences Department at Emory University, Atlanta, GA, USA.

\section{Availability of data and materials}

The datasets analyzed will be made available upon request. Model code is available in Additional file 1.

\section{Authors' contributions}

WTK conducted experiments and developed the focal-stage matrix projection model. GVP provided advice on study design and model development. Both authors wrote and proofed the manuscript. Both authors read and approved the final manuscript.

Ethics approval and consent to participate Not applicable.
Consent for publication

Not applicable.

\section{Competing interests}

The authors declare that they have no competing interests.

\section{Publisher's Note}

Springer Nature remains neutral with regard to jurisdictional claims in published maps and institutional affiliations.

Received: 15 November 2017 Accepted: 14 February 2018

Published online: 27 February 2018

References

1. Andreadis TG. The contribution of Culex pipiens complex mosquitoes to transmission and persistence of West Nile virus in North America. J Am Mosq Control Assoc. 2012;28(4s):137-51.

2. Diuk-Wasser MA, Molaei G, Simpson JE, Folsom-O'Keefe CM, Armstrong PM, Andreadis TG. Avian communal roosts as amplification foci for West Nile virus in urban areas in northeastern United States. Am J Trop Med Hyg. 2010:82(2):337-43.

3. Molaei G, Huang S, Andreadis TG. Vector-host interactions of Culex pipiens complex in northeastern and southwestern USA. J Am Mosq Control Assoc. 2012;28(4s):127-36.

4. Kilpatrick AM, Kramer LD, Campbell SR, Alleyne AO, Dobson AP, Daszak P. West Nile virus risk assessment and the bridge vector paradigm. Emerg Infect Dis. 2005;11(3):425-9.

5. Liu H, Weng Q, Gaines D. Geographic incidence of human West Nile virus in northern Virginia, USA, in relation to incidence in birds and variations in urban environment. Sci Total Environ. 2011;409(20):4235-41.

6. Savage HM, Aggarwal D, Apperson CS, Katholi CR, Gordon E, Hassan HK, et al. Host choice and West Nile virus infection rates in blood-fed mosquitoes, including members of the Culex pipiens complex, from Memphis and Shelby County, Tennessee, 2002-2003. Vector Borne Zoonotic Dis. 2007;7(3):365-86.

7. Vazquez-Prokopec GM, Vanden Eng JL, Kelly R, Mead DG, Kolhe P, Howgate J, et al. The risk of West Nile virus infection is associated with combined sewer overflow streams in urban Atlanta, Georgia, USA. Environ Health Perspect. 2010;118(10):1382-8.

8. Harbison JE, Henry M, Xamplas C, Dugas LR. Evaluation of Culex pipiens populations in a residential area with a high density of catch basins in a suburb of Chicago, Illinois. J Am Mosq Control Assoc. 2014;30(3):228-30.

9. Harbison JE, Sinacore JM, Henry M, Xamplas C, Dugas LR, Ruiz MO. Identification of larvicide-resistant catch basins from three years of larvicide trials in a suburb of Chicago. IL Environ Health Insights. 2014;8(S2):1-7.

10. Su T, Cheng M-L, Melgoza A, Thieme J. Laboratory and field evaluations of MosquironB. 0.12CRD, a new formulation of novaluron, against Culex mosquitoes. J Am Mosq Control Assoc. 2014;30(4):284-90.

11. Harbison JE, Corcoran PC, Runde A, et al. Variable efficacy of extendedrelease mosquito larvicides observed in catch basins in the Northeast Chicago metropolitan area. Environ Health Insights. 2016;10:65-8.

12. Beehler JW, Mulla MS. Effects of organic enrichment on temporal distribution and abundance of culicine egg rafts. J Am Mosq Control Assoc. 1995; 11(2 Pt 1):167-71

13. Mogi M, Sota T. Physical and biological attributes of water channels utilized by Culex pipiens pallens immatures in Saga City, southwest Japan. J Am Mosq Control Assoc. 1996;12(2 Pt 1):206-14.

14. Hamer GL, Chaves LF, Anderson TK, Kitron UD, Brawn JD, Ruiz MO, et al. Fine-scale variation in vector host use and force of infection drive localized patterns of West Nile virus transmission. PLoS One. 2011;6(8):e23767.

15. Dadd RH. Amino acid requirements of the mosquito Culex pipiens: asparagine essential. J Insect Physiol. 1978;24(1):25-30.

16. Dadd RH. Essential fatty acids for the mosquito Culex pipiens. J Nutr. 1980; 110(6):1152-60.

17. Ponnusamy L, Xu N, Nojima S, Wesson DM, Schal C, Apperson CS. Identification of bacteria and bacteria-associated chemical cues that mediate oviposition site preferences by Aedes aegypti. Proc Natl Acad Sci USA. 2008;105(27):9262-7.

18. Merritt RW, Dadd RH, Walker ED. Feeding behavior, natural food, and nutritional relationships of larval mosquitoes. Annu Rev Entomol. 1992;37:349-76. 
19. McCann S, Day JF, Allan S, Lord CC. Age modifies the effect of body size on fecundity in Culex quinquefasciatus Say (Diptera: Culicidae). J Vector Ecol. 2009;34(2):174-81.

20. Farajollahi A, Fonseca DM, Kramer LD, Marm Kilpatrick A. "bird biting" mosquitoes and human disease: a review of the role of Culex pipiens complex mosquitoes in epidemiology. Infect Genet Evol. 2011;11(7): 1577-85.

21. Yoshioka M, Couret J, Kim F, McMillan JR, Burkot TR, Dotson EM, Kitron UD, Vazquez-Prokopec GM. Diet and density dependent competition affect larval performance and oviposition site selection in the mosquito species Aedes albopictus (Diptera: Culicidae). Parasit Vectors. 2012;5:225.

22. Chaves LF, Keogh CL, Nguyen AM, Decker GM, Vazquez-Prokopec GM, Kitron UD. Combined sewage overflow accelerates immature development and increases body size in the urban mosquito Culex quinquefasciatus. J Appl Entomol. 2011;135(8):611-20.

23. Chaves LF, Keogh CL, Vazquez-Prokopec GM, Kitron UD. Combined sewage overflow enhances oviposition of Culex quinquefasciatus (Diptera: Culicidae) in urban areas. J Med Entomol. 2009;46(2):220-6.

24. Lampman RL, Novak RJ. Oviposition preferences of Culex pipiens and Culex restuans for infusion-baited traps. J Am Mosq Control Assoc. 1996;12(1):23-32.

25. Reiskind MH, Wilson ML. Culex restuans (Diptera: Culicidae) oviposition behavior determined by larval habitat quality and quantity in southeastern Michigan. J Med Entomol. 2004;41(2):179-86.

26. Calhoun LM, Avery M, Jones L, Burkot TR. Combined sewage overflows (CSO) are major urban breeding sites for Culex quinquefasciatus in Atlanta, Georgia. Am J Trop Med Hyg. 2007;77(3):478-84.

27. Curtis CF, Feachem RG. Sanitation and Culex pipiens mosquitoes: a brief review. J Trop Med Hyg. 1981;84(1):17-25.

28. Reisen WK, Takahashi RM, Carroll BD, Quiring R. Delinquent mortgages, neglected swimming pools, and West Nile virus, California. Emerg Infect Dis. 2008;14(11):1747-9.

29. Agnew P, Haussy C, Michalakis Y. Effects of density and larval competition on selected life history traits of Culex pipiens quinquefasciatus (Diptera: Culicidae). J Med Entomol. 2000;37(5):732-5.

30. Reiskind MH, Walton ET, Wilson ML. Nutrient-dependent reduced growth and survival of larval Culex restuans (Diptera: Culicidae): laboratory and field experiments in Michigan. J Med Entomol. 2004;41(4):650-6.

31. Roberts D. Overcrowding of Culex sitiens (Diptera: Culicidae) larvae: population regulation by chemical factors or mechanical interference. J Med Entomol. 1998:35(5):665-9.

32. Wynn G, Paradise CJ. Effects of microcosm scaling and food resources on growth and survival of larval Culex pipiens. BMC Ecol. 2001;1:3-3.

33. Campbell A, Sinha RN. Bioenergetics of granivorous beetles, Cryptolestes ferrugineus and Rhyzopertha dominica (Coleoptera: Cucujidae and Bostrichidae). Can J Zool. 1978;56(4):624-33.

34. Farrar RR, Barbour JD, Kennedy GG. Quantifying food consumption and growth in insects. Ann Entomol Soc Am. 1989;82(5):593-8.

35. Lebl K, Brugger K, Rubel F. Predicting Culex pipiens/restuans population dynamics by interval lagged weather data. Parasit Vectors. 2013;6:129.

36. Koenraadt CJ, Harrington LC. Flushing effect of rain on container-inhabiting mosquitoes Aedes aegypti and Culex pipiens (Diptera: Culicidae). J Med Entomol. 2008;45(1):28-35

37. Ruiz MO, Chaves LF, Hamer GL, Sun T, Brown WM, Walker ED, et al. Local impact of temperature and precipitation on West Nile virus infection in Culex species mosquitoes in northeast Illinois, USA. Parasit Vectors. 2010;3:19.

38. Shand L, Brown WM, Chaves LF, Goldberg TL, Hamer GL, Haramis L, et al. Predicting West Nile virus infection risk from the synergistic effects of rainfall and temperature. J Med Entomol. 2016;53:935-44.

39. Gardner AM, Hamer GL, Hines AM, Newman CM, Walker ED, Ruiz MO. Weather variability affects abundance of larval Culex (Diptera: Culicidae) in storm water catch basins in suburban Chicago. J Med Entomol. 2012;49(2):270-6.

40. Marini G, Poletti P, Giacobini M, Pugliese A, Merler S, Rosá R. The role of climatic and density dependent factors in shaping mosquito population dynamics: the case of Culex pipiens in northwestern Italy. PLoS One. 2016;11(4):e0154018.

41. Harrison B, Byrd BD, Sither, CB, Whitt, PB. A key to the mosquitoes of North Carolina and the Mid-Atlantic States. Cullowhee: Western Carolina University Mosquito \& Vector-borne Infectious Disease Laboratory: North Carolina Agricultural Extension Service; 2005.

42. Kaplan EL, Meier P. Nonparametric estimation from incomplete observations. J Am Stat Assoc. 1958:53(282):457-81.
43. Lefkovitch LP. The study of population growth in organisms grouped by stages. Biometrics. 1965;21(1):1-18.

44. Ciota AT, Matacchiero AC, Kilpatrick AM, Kramer LD. The effect of temperatue on life history traits of Culex mosquitoes. J Med Entomol. 2014;51(1):55-62

45. Team RC. R: a language and environment for statistical Computing 2013. http://www.R-project.org/.

46. Munstermann LE, Craig GB. Culex mosquito populations in the catch basins of northern St. Joseph County, Indiana. Proc Indiana Acad Sci. 1977;86:246-52.

47. de Oliveira CM, Filho FC, Beltran JE, Silva-Filha MH, Regis L. Biological fitness of a Culex quinquefasciatus population and its resistance to Bacillus sphaericus. J Am Mosq Control Assoc. 2003;19(2):125-9.

48. Anderson JF, Ferrandino FJ, Dingman DW, Main AJ, Andreadis TG, Becnel JJ. Control of mosquitoes in catch basins in connecticut with Bacillus thuringiensis israelensis, Bacillus sphaericus, and spinosad. J Am Mosq Control Assoc. 2011;27(1):45-55

49. PAd G, Cole JJ. Bacterial growth efficiency in natural aquatic systems. Annu Rev Ecol Syst. 1998;29(1):503-41.

50. Yee DA, Kaufman MG, Juliano SA. The significance of ratios of detritus types and micro-organism productivity to competitive interactions between aquatic insect detritivores. J Anim Ecol. 2007;76(6):1105-15.

51. Mbare O, Lindsay SW, Fillinger U. Pyriproxyfen for mosquito control: female sterilization or horizontal transfer to oviposition substrates by Anopheles gambiae sensu stricto and Culex quinquefasciatus. Parasit Vectors. 2014;7:280.

52. Cailly P, Tran A, Balenghien T, Lb. A climate-driven abundance model to assess mosquito control strategies. Ecol Model. 2012;227:7-17.

53. Knepper RG, Leclair AD, Strickler JD, Walker ED. Evaluation of methoprene (Altosid XR) sustained-release briquets for control of culex mosquitoes in urban catch basins. J Am Mosq Control Assoc. 1992;8(3):228-30.

54. McAbee RD, Kang KD, Stanich MA, Christiansen JA, Wheelock CE, Inman AD, Hammock BD, Cornel AJ. Pyrethroid tolerance in Culex pipiens pipiens var. molestus from Marin County, California. Pest Manag Sci. 2004;60(4):359-68.

55. Paul A, Harrington LC, Zhang L, Scott JG. Insecticide resistance in Culex pipiens from New York. J Am Mosq Control Assoc. 2005:21(3):305-9.

56. Taskin BG, Dogaroglu T, Kilic S, Dogac E, Taskin V. Seasonal dynamics of insecticide resistance, multiple resistance, and morphometric variation in field populations of Culex pipiens. Pestic Biochem Physiol. 2016;129:14-27.

57. Vasquez MI, Violaris M, Hadjivassilis A, Wirth MC. Susceptibility of Culex pipiens (Diptera: Culicidae) field populations in Cyprus to conventional organic insecticides, Bacillus thuringiensis subsp. israelensis, and methoprene. J Med Entomol. 2009;46(4):881-7.

58. Xue R-D, Qualls WA, Phillips JD, Zhao T-Y. Insecticidal activity of five commercial mosquito coils against Anopheles albimanus, Aedes albopictus, and Culex quinquefasciatus. J Am Mosq Control Assoc. 2012;28(2):131-3.

59. Souza RL, Mugabe VA, Paploski IAD, Rodrigues MS, Moreira PSDS, Nascimento LCG, et al. Effect of an intervention in storm drains to prevent Aedes aegypti reproduction in Salvador, Brazil. Parasit Vectors. 2017;10:328.

\section{Submit your next manuscript to BioMed Central and we will help you at every step:}

- We accept pre-submission inquiries

- Our selector tool helps you to find the most relevant journal

- We provide round the clock customer support

- Convenient online submission

- Thorough peer review

- Inclusion in PubMed and all major indexing services

- Maximum visibility for your research

Submit your manuscript at www.biomedcentral.com/submit 